\title{
Espacios femeninos de escritura en la Edad Media
}

Desde hace años ha existido una corriente historiográfica que se ha ocupado, y preocupado, por indagar en todo lo referente al mundo de la mujer desde amplias perspectivas históricas, sociológicas o culturales. Numerosos trabajos han puesto de relieve las dispares circunstancias que las mujeres experimentaron en los distintos tiempos históricos, subrayando el protagonismo que algunas de ellas tuvieron en determinados contextos como sujetos extraordinarios, capaces de afrontar cambios significativos en sus respectivos entornos. En esta tesitura, la escritura, y su uso aplicado a diferentes finalidades, representa un elemento identificativo que permite pulsar las diferentes realidades que experimentaron las mujeres en una cronología concreta: la Edad Media.

Durante ese amplio período de tiempo, la escritura femenina aparece indisolublemente unida a varios espacios. De esta forma, se puede distinguir un espacio geográfico asociado a realidades religiosas y políticas distintas. Para el caso de la Península Ibérica, parece conveniente señalar la civilización islámica y la cristiana, ambas con concepciones distintas sobre el uso de la escritura por la mujer. También puede atenderse al espacio físico como el lugar en el que se desarrolló la escritura: un espacio doméstico, profesional o religioso, siendo susceptibles de permitir cierta categorización tipológica sobre qué se escribía. Finalmente, no hay que obviar un espacio más reducido, pero también importante, que es el que puede identificarse en el propio soporte. En este sentido, hay evidencias de escrituras femeninas en tratados, códices $u$ otros libros y documentos que fueron anotados, comentados, firmados (notas de propiedad) o glosados.

Desde esta perspectiva, los tres espacios condicionaron la escritura en general, y la femenina en particular. La creación por parte de mujeres copistas de códices se realizó, por norma general, en centros especializados; las epístolas o las cartas, un género más extendido de lo que en un principio podría adivinarse, se desarrollaron en un ambiente más doméstico, mientras que las glosas, comentarios y otro tipo de anotaciones, hechas directamente sobre el libro o el documento, abren un complejo abanico de posibilidades dignas de estudio y análisis, acercándonos al mundo interior de sus propietarias.

Todavía, en la segunda mitad del siglo XVI, un franciscano llamado Joan de la Cerda trataba de dilucidar, en una obra de carácter moralista orientada a la

Pablo Alberto Mestre Navas, Universidad de Sevilla

2 Open Access. (C) 2018 Pablo Alberto Mestre Navas, published by De Gruyter. (c) BY-NC-ND This work is licensed under the Creative Commons Attribution-NonCommercial-NoDerivatives 4.0 License. https://doi.org/10.1515/9783110596755-040 
educación de las mujeres de diferentes estados, si éstas debían aprender o no, a escribir. Este autor no tenía dudas sobre la utilidad que tenía la enseñanza de la lectura como un instrumento salvífico para el alma, bien entendido que ésta debía ser, sobre todo, una lectura religiosa, personal o comunitaria, que alejara a la mujer de las pasiones perniciosas del mundo. A este respecto, apuntaba el franciscano, que la enseñanza de tales prácticas debía estar en manos de religiosos o maestros ancianos, en presencia de otras personas.

A pesar de las disquisiciones a las que llega a lo largo de todo el manuscrito, Joan de la Cerda, finalmente, y tras una genial exposición ejemplarizante en la que enumeraba multitud de mujeres que escribieron desde la Antigüedad, no se oponía a ello, aunque con algunas reservas:

Auemos visto en nuestros tiempos de saber leer doncellas y otras damas escreuir auerse seguido grandes inconvenientes, que de tener la pluma en la mano se recreçen, mas porque es exercicio indiferente, yo no le quiero condemnar. ${ }^{1}$

No hay duda que la concepción cristiana marcó un antes y un después en el uso de la escritura por parte de la mujer. Desde los tiempos del apóstol San Pablo se creó una corriente en la que se insistía en la necesidad de establecer espacios específicos destinados a la educación de la mujer, generándose todo tipo de acalorados debates sobre la necesidad de si éstas debían aprender a escribir. La controversia, como se ha visto, perduró durante buena parte del Antiguo Régimen, aunque fue en el siglo XIII cuando Santo Tomás de Aquino distinguió entre educación pública y privada, quedando la mujer relegada a la segunda. ${ }^{2}$ Por tanto, sería en un ámbito privado donde se vertebró, en esencia, la educación femenina, siempre sometida a la estricta observancia de los principios cristianos y bajo la supervisión de clérigos o maestros que eran contratados.

Empero fue, precisamente, en este ambiente religioso en donde se encuentran numerosos ejemplos de mujeres que emplearon la escritura dentro un contexto monástico. La consagración de las mujeres a la vida religiosa permitió el acceso a la lectura y a la escritura, ya que la lectio divina constituía una de las actividades básicas para las comunidades monásticas.

$1 \mathrm{~J}$. de la Cerda, Libro intitulado vida política de todos los estados de mugeres, en el qual se dan prouechosos y christianos documentos y cursos para criarse y conservarse deuidamente las mugeres en sus estados, Alcalá de Henares, Iuan Gracián, 1599. Para este trabajo se ha utilizado el ejemplar manuscrito que se conserva en la Biblioteca Nacional de España, ya que contiene innumerables correcciones y anotaciones hechas por el mismo autor que no fueron objeto de publicación (BNE. Mss. 19212, f. 6v).

2 C. Cuadra et al., Notas a la educación de las mujeres en la Edad Media, in Las sabias mujeres: educación, saber y autoría, Madrid, A. C. Al-Mudayna, 1994, p. 39. 
En torno al fenómeno del monacato proliferaron diferentes reglas que vertebraron la vida cotidiana de vírgenes y mujeres consagradas a Dios. Los precursores de las reglas monásticas, así como de la educación de las religiosas, surgieron en Oriente, siendo Tertuliano y Cipriano los que dieron principio a una tradición doctrinal y normativa que se sustentaba en compilaciones de sermones, tratados y algunas epístolas en las que se daban pautas sobre modelos de conducta, ejercicios espirituales o prácticas devocionales.

Desde los primeros tiempos del cristianismo, la epístola demostró ser uno de los instrumentos propagadores más eficaces, ampliándose sustancialmente las redes de comunicación y los horizontes vivenciales. La epístola sirvió para compartir experiencias religiosas, ideas, doctrinas y modos de vida por parte de la patrística y las comunidades consagradas de la Edad Media, que vieron en la epístola un vehículo ideal para romper las distancias y conversar por escrito, lo que conciliaba con el rigor del silencio monástico. Sin duda, el soporte de escritura imponía limitaciones de espacio, por lo que se debía estructurar bien el contenido, la simpleza y la profundidad del mensaje. Hay quien ha querido ver, no sin razón, algunas características que permitirían una clasificación a tenor del contenido. De este modo, Rita Queiroz ha podido distinguir entre "cartas de vocación”, “cartas de exhortación”, “cartas de consolación”, “cartas de dirección”, "cartas comerciales”, “cartas de recomendación” y "cartas de fallecimiento". 3

La epístola también fue una herramienta habitual para la mujer durante la Edad Media. Muchas de las cartas de los santos padres estuvieron dirigidas a algunas mujeres principales en contestación de otras que ellos habían recibido. Uno de los casos más paradigmáticos lo constituyen las cartas de San Agustín de Hipona, escribiendo entre los años 411 y 423 hasta doce cartas dirigidas a alguna comunidad religiosa y a otras mujeres, entre las que nombra a Albina, Proba, Paulina, Juliana o Felicia.

De los textos agustinianos se desprende que muchas de las cartas dirigidas a las citadas eran una repuesta a otras que él mismo había recibido por parte de éstas; así en la carta CL, dirigida a Proba y Juliana entre los años 413 o 414 decía:

Habéis llenado de gozo mi corazón, con tanta mayor dulzura cuanto fue mayor la caridad, tanto más grata cuanto más prontamente. Sois conocidas en todas partes. La fama volandera predica por doquier la santidad virginal de vuestra estirpe, pero con el anuncio más fiel y seguro de vuestra carta os habéis anticipado a las veloces alas de la fama: me habéis hecho exultar con el conocimiento de tan excelente bien antes de que me sobrecogiese la duda al oírlo. ¿Quién explicará con palabras, quién ensalzará con la debida apología, cuán

3 R. Queiroz, Tres tratados medievales portugueses del texto "Castillo peligroso", in La correspondencia en la Historia. Modelos y prácticas de la escritura epistolar. Actas del VI Congreso Internacional de Historia de la Cultura Escrita, Madrid, Calambur, 2002, vol. I, pp. 70-71. 
incomparablemente es más glorioso y fecundo el que Cristo tenga algunas mujeres vírgenes de vuestra sangre que el que el mundo haya tenido varones cónsules de ella? Si es grande y noble señalar con el propio nombre los ciclos del tiempo, ¿cuánto más y más noble será traspasar los tiempos con la integridad del corazón y del cuerpo? Alégrese, pues, la muchacha, noble por su linaje y más noble por su santidad, porque ha de conseguir en los cielos una excelsa ventaja por su unión con Dios, mucho más que si propagase un sublime linaje por su unión con un hombre. ${ }^{4}$

No hay duda de que San Agustín, y algunas de las mujeres con las que solía establecer contacto por este medio, mantuvieron discusiones doctrinales y de conducta, llegando el santo a reproducir el texto con exactitud que él recibía. No en vano, en la carta CLXXXVIII, dirigida a Juliana y escrita entre comienzos del año 417 o principios del 418, San Agustín la amonesta encarecidamente sobre algunos particulares:

\begin{abstract}
Siendo esto así, nadie nos tendrá por malignos si por nuestra más estrecha relación nos preocupamos, más de amonestaros a que evitéis las opiniones contrarias a la gracia de Dios. El apóstol nos manda insistir en la predicación no sólo con oportunidad, sino también sin ella. Pero a vosotras no os contamos en el número de aquellos a quienes nuestra palabra o escritura puede parecer importuna, cuando os amonestamos a evitar con cautela lo que no pertenece a la sana doctrina. Por eso recibisteis nuestra amonestación con ánimo tan grato, que en la carta a la que ahora contestamos, dices: «Vuestra Reverencia me amonesta a que no abra mis oídos a esos hombres que con frecuencia corrompen la fe venerable con impías discusiones. Os doy mil gracias por tan piadoso aviso.... ${ }^{5}$
\end{abstract}

De las cartas agustinianas se entresaca la existencia de esa reciprocidad en la correspondencia que el santo mantenía con algunas mujeres de la alta sociedad, si bien no resulta sencillo adivinar si las epístolas femeninas respondían solo a una creación intelectual de éstas o, además, también fueron escritas por ellas.

En cualquier caso, el arte de la escritura no fue ajeno a la mujer durante la Edad Media. Como se ha indicado, la proliferación de reglas monásticas por Europa, sobre todo a partir del siglo VI, demuestran la existencia de copistas femeninas. Una de las primeras reglas destinada a mujeres fue la que creó en el siglo VI Cesáreo de Arlés -Regula virginum-, en la que se transigía el ingreso de niñas mayores de seis años en los monasterios para que fuesen criadas y educadas bajo preceptos religiosos y buenas costumbres. Aunque las principales ocupaciones de las monjas lo constituían la hilatura de la lana o la hechura de sus propios vestidos, es obvio que la oración y la lectio divina fueron la razón de ser

4 L. Cilleruelo, De San Agustín, Madrid, Editorial Católica, 1953, t. XI, p. 317.

5 Ibid., p. 739. 
de los monasterios que surgieron por parte de Europa, adoptando abiertamente la que, puede considerarse, como primera regla netamente femenina.

Pero en el monasterio de Arlés también existió un importante scriptoria en el que las monjas desarrollaron labores de copistas, llegando a encargar el obispo de lugar que fuesen ellas las que, con pulcritud, copiasen las Sagradas Escrituras inter psalmos et jejunia, vigilias quoque ac lections libros divinos pulchre scriptitent virgines Christi - .

A las de Cesáreo de Arlés le siguieron las de San Leandro de Sevilla, Waldaberto de Luxeuil o las del obispo de Besançon, Donato. Estas reglas eran una sucesión de pautas de conductas y advertencias de lo que se debía o no hacer en una comunidad de religiosas. En el caso de la regla de Leandro, que dedicó a su hermana Florentina, fundadora de un monasterio en la localidad de Écija, el obispo hispalense trataba de explicar cómo se podía perseverar en la prudencia, cuándo debían tomarse los baños o las dietas y ayunos, exaltando siempre la virginidad como un don inigualable de Dios. No existen, por tanto, de forma explícita, obligaciones que exigían a las monjas tareas asociadas con la escritura. ${ }^{6}$

Uno de los casos más célebres de escritura femenina en España es el de la monja Leodegundia, que escribió parte de un códice que contenía cartas de San Jerónimo, el capítulo setenta y siete de la regla de San Pacomio -Sententia de regula devotarum-, fragmentos de escritos de San Agustín o las reglas de San Isidoro y San Leandro de Sevilla, es decir un cúmulo de textos orientados a la regulación normativa de la vida comunitaria de religiosas. ${ }^{7}$

El Liber o Codex Regularum es uno de los casos aislados en los que puede identificarse la autoría femenina gracias a la suscripción, en la que quedó constancia del lugar, la fecha y el nombre de la copista -O vos onmes qui legentis hunc codicem, mementote clientula et exigua Leodegundia qui hunc scripsi in monasterio Bobatelle, regnante Adefonso principe in era DCCCL-. Este códice comparte el estilo mozárabe en su decoración, en la que se distinguen los tradicionales juegos cromáticos yuxtapuestos en bandas horizontales, con otro libro en el que trabajó como ilustradora Ende, en compañía de los presbíteros Emeterio, pintor, y el calígrafo Senior.

6 San Leandro, Instrucción y regla del B. San Leandro, arçobispo de Sevilla, a su ermana santa Florentina. Traduzida de latín en castellano por el P. Martín de Roa, de la Compañía de Iesús, Sevilla, Matías Clavijo, 1629.

7 C. Cuadra, La educación de las vírgenes cristianas en las reglas primitivas, in Las sabias mujeres: educación, saber y autoría, Madrid, A. C. Al-Mudayna, 1994, pp. 65-66. 
Podría decirse que Ende representa, en la historia del libro manuscrito en Europa, la primera presencia femenina con "con plena intención artística". ${ }^{8}$ Las ilustraciones del Beato de Gerona, que contiene el Comentario al Apocalipsis de Beato de Liébana, representan uno de los ejemplos de mayor refinamiento del panorama peninsular.

Aunque los espacios religiosos supusieron un revulsivo para la participación de la mujer en el circuito de la producción libraria en la Cristiandad europea, siguen escaseando noticias que permitan poner en valor la dimensión que pudo llegar a alcanzar el fenómeno. La cuestión de la autoría es un problema que se extiende por buena parte de la Edad Media y, ni siquiera la mayoría de los copistas tenían asumido la importancia del rol que ellos desempeñaban, por lo que no era habitual firmar o dejar constancia del trabajo que uno realizaba. Por otra parte, la escasa documentación que se conserva de monasterios durante la Alta y Plena Edad Media son pergaminos referentes a testamentos, privilegios, donaciones, trueques o compraventas. En este sentido, los archivos monásticos que cuentan con un fondo mayor son aquellos que han conservado lo que la archivística denomina tesoro de cartas, es decir, documentos de privilegios, facultades y derechos con los que la institución hacía valer sus prerrogativas jurídicas.

Desde esta perspectiva, parece razonable pensar que en los monasterios femeninos debió existir una producción documental vinculada a la administración y al gobierno del centro. Pese a que esto fue una realidad, muchos monasterios y conventos dejaron en manos de personas ajenas a la institución el proveimiento y despacho de estos negocios. Quizás no tanto porque no supiesen escribir, como porque fue práctica habitual que contasen con mayordomos u otro personal subalterno que les ayudase a la administración de propiedades, la cobranza de los arrendamientos o asuntos de diversa índole. Con todo, como quiera que muchos de esos pergaminos que se han conservado se circunscriben a una tipología concreta (testamentos, cartas de pago, trueques, donaciones o compraventas), fue necesario la intervención de un escribano público o notario, motivo por el que ellos mismos escribían los documentos.

Pese a que los negocios se despechaban delante de fedatarios públicos, existen onerosas ocasiones en los que pueden hallarse suscripciones de algunas abadesas y comunidades monásticas, lo que se hacía constar con expresiones que aludían al acto jurídico en sí, seguido de alguna marca holográfica.

Al margen de las prácticas de escritura, uno de los fenómenos que más influyó en la lectura religiosa en el ámbito doméstico fue la aparición del libro de

8 M. López, Presencia femenina en las artes del libro español, Madrid, Fundación Universitaria Española, 1976, p. 18. 
horas. Alguno de los aspectos que aquí interesa señalar son las ilustraciones que aparecen representando a María y otras santas en actitud orante, sosteniendo entre sus manos un libro devocional. La Virgen suele protagonizar dos escenas: la Anunciación y Pentecostés. En ambas hay una predilección por resaltar el ademán orante, realizando una lectura que hay que interpretar como personal la Anunciación - , y otra dirigiendo las plegarias a través de una lectura comunitaria - Pentecostés - .

El hecho de que María, modelo ideal de imitación para la mujer cristiana, apareciera en escenas domésticas leyendo nos aporta una visión esclarecedora de los valores medievales con respecto al papel femenino. La lectura de libros piadosos como instrumento salvífico fue una práctica extendida. Tampoco debe sorprender otra tierna escena en la que se representaba a Santa Ana enseñando a leer a la Virgen, lo que subrayaba la labor educacional de las madres como una tarea cotidiana. ${ }^{9}$

Aunque en los espacios monásticos las lecturas debían tener una temática afín, con el tiempo se fueron introduciendo algunos libros de carácter profano. En este sentido, en 1740, el dominico fray Jaime Baron y Arin se hacía eco de estas prácticas mediante una parábola que simulaba un diálogo entre Agna e Instrucción:

Con razón, señora, lo suspendéis, porque en mi convento no se permiten tales libros. Un año he vivido en él y no los he visto, ni oído, que alguna monja los tenga.

[...] Dices que no se permiten en tu convento tales libros. O simplica e inocente criatura! Pues juzgas tú, que en un convento religioso, aunque muy observante, no se hace, sino lo que la regla, las leyes o lo prelados permiten? Vives engañada, y claramente lo conocerás, a mediana reflexión que hagas. Se hace, pues, en los conventos, algunas veces, lo mismo que se prohíbe o no se permite. Esto se acostumbra hacer ocultamente, escondiéndose, cerradas las puertas, o a solas, o en compañía de las que gustan ocuparse en lo que en lo público no se les permitiría. Cree, que de este modo hay algunas que ocupan mal el tiempo, en leer dichos libros, y si otras se retiran, o se encierran, para que no les embaracen los exercicios particulares de devoción. ${ }^{10}$

Pero, si durante la Edad Media la enseñanza de la escritura a la mujer no se contemplaba como un elemento esencial de su aprendizaje en la órbita cristiana porque se pensaba en que se haría un mal uso de ella, tal y como escribió a finales del siglo XVI el franciscano Juan de la Cerda en su citado tratado, alegando que

9 A. Manguel, Una historia de la lectura, Madrid, Alianza Editorial, 2003, p. 110.

$10 \mathrm{~J}$. Baron, La religiosa enseñada y entretenida en las obligaciones de su noble espiritual estado de esposa del Rey del Cielo, Madrid, Gabriel Ramírez, 1740, p. 131. 
serviría de ocasión para que respondiesen las cartas de los hombres, ${ }^{11}$ en el sur peninsular se estaba produciendo un fenómeno distinto.

De hecho, en Al-Andalus existieron escuelas familiares y coránicas en las que sí se enseñaba a escribir y a leer los textos sagrados. Aunque en su mayoría fueron escuelas masculinas, éstas coexistieron con otras mixtas. Llegó a establecer una especie de certificado, llamado iyaza, que se expedía por parte de un maestro a una alumna para que ésta pudiese transmitir sus conocimientos a un tercero. ${ }^{12}$

Desde el siglo XIV se percibe un aumento de la producción libraria y documental tanto en los ámbitos eclesiásticos como laicos. Cabe destacar la proliferación de cartas que existió entre mujeres cortesanas. La práctica de escribir se extendió considerablemente en el ámbito cortesano hasta límites insospechados. Para pulsar esta realidad, algunos catálogos documentales, como el del Archivo General de la Casa Ducal de Medinaceli, ${ }^{13}$ permiten contabilizar el volumen de la correspondencia entre mujeres de alta cuna con la Corona, muchas de ellas hológrafas.

11 Así escribía el franciscano sobre este particular: "En lo que a si es bien ocupar a la doncella en el exercicio de leer y escrebir: a hauido diuersos pareceres y, examinados los fundamientos (sic) de estas opiniones, parece que, aunque es bien que aprenda a leer para que reçe y lea buenos libros, mas, el escreuir ni es necesario ni lo querría ver en las mugeres, no porque ello de suyo sea malo, sino porque tienen la ocasión en las manos de escreuir billetes y responder a los que hombres les escribían. Muchas ay que saben este exerçicio y vsan dél tan mal, que no sería de pareçer que lo aprendiessen todas” (J. de la Cerda, cit., f. 6v).

12 G. López, Mujeres educadas/mujeres cultas: regla o libre elección en el Islam andalusí, in De leer a escribir. La educación de las mujeres: ¿libertad o subordinación?, Madrid, Al-Mudayna, 1996, pp. 9-11.

13 J. González, Catalogo del Archivo General de la Casa Ducal de Medinaceli, Sevilla, Caja de Ahorros de Sevilla, 1969-1973, 3 vol. 